\title{
Enhanced survival of lung granulocytes in an animal model of asthma: evidence for a role of GM-CSF activated STAT5 signalling pathway
}

\author{
R K Turlej, L Fiévez, C F Sandersen, S Dogné, N Kirschvink, P Lekeux, F Bureau
}

\begin{abstract}
Background-As granulocyte/macrophage colony stimulating factor (GM-CSF) mediated delay of granulocyte apoptosis contributes to the accumulation of inflammatory cells at the site of inflammation in many diseases, we sought to determine whether asthma is also associated with a GM-CSF dependent increase in lung granulocyte survival. Moreover, because GM-CSF mediates its effects through activation of signal transducer and activator of transcription 5 (STAT5), we also investigated the potential role of STAT5 in allergic inflammation.

Methods-Blood granulocytes were recovered from six healthy and six heaves affected horses, a model of asthma. Lung granulocytes were obtained by bronchoalveolar lavage (BAL) from the same horses. Granulocytes were cultured in the presence or absence of anti-GM-CSF receptor antibodies for different times and apoptosis was determined using the Annexin-V/propidium iodide detection method. Nuclear protein extracts from cultured granulocytes were analysed for STAT5 binding activity by electrophoretic mobility shift assay.
\end{abstract}

Results-BAL fluid granulocytes from heaves affected horses demonstrated a significant delay in apoptosis compared with blood granulocytes from the same horses and blood and BAL fluid granulocytes from healthy horses. Conversely, the rate of apoptosis in blood granulocytes from healthy and heaves affected horses was comparable. The enhanced survival of BAL fluid granulocytes from affected horses was suppressed in the presence of antibodies directed against GM-CSF receptors. Increased levels of active STAT5 were found in BAL fluid granulocytes from heaves affected horses and were markedly reduced after treatment with anti-GM-CSF receptor antibodies.

Conclusions-These data indicate that granulocyte survival is enhanced in the lung of heaves affected horses and suggest a role for a GM-CSF activated STAT5 pathway in delaying apoptosis of lung granulocytes in this model of asthma.

(Thorax 2001;56:696-702)

Keywords: asthma; apoptosis; granulocytes

Received 4 December 2000 Returned to authors

7 March 2001

Revised version received

19 April 2001

Accepted for publication

21 May 2001 mechanisms by which inflammation persists in asthmatic airways are not completely understood. Recent ex vivo experiments have clearly shown that blood and lung neutrophils from patients with airway inflammatory diseases such as cystic fibrosis, idiopathic fibrosis, pneumonia, and lung cancer associated with neutrophilia demonstrate a delay in apoptosis, the most common form of programmed cell death. ${ }^{2}$ It was therefore concluded that this phenomenon probably contributes to the accumulation of neutrophils at the site of inflammation. Similar ex vivo experiments have not been performed with lung granulocytes obtained from asthmatic patients. However, the findings that blood eosinophil apoptosis is delayed in inhalant allergy ${ }^{34}$ and that the number of apoptotic eosinophils is low in the bronchi of asthmatic subjects and is inversely correlated with disease severity ${ }^{5}$ suggest that enhanced granulocyte survival is also a feature of the pathogenesis of persistent airway inflammation in asthma.

In vitro studies have shown that numerous inflammatory mediators are able to regulate the life span of purified granulocytes. Among these mediators, granulocyte/macrophage colony stimulating factor (GM-CSF), which is overexpressed in asthmatic airways, ${ }^{6}$ potently delays granulocyte apoptosis. ${ }^{7}$ GM-CSF mediates its effects through binding to a receptor made up of two distinct subunits, referred to as $\alpha$ and $\beta .^{89}$ In granulocytes, activation of the transducing $\beta$ subunit of the GM-CSF receptor leads to specific activation of several tyrosine kinases including Lyn, Fes, and Jak2, a member of the Janus family of tyrosine kinases. ${ }^{10-13}$ Moreover, specific prevention of GM-CSF mediated Jak2 activation is associated with the inability of GM-CSF to enhance eosinophil survival, indicating that Jak2 is essential for GM-CSF induced delay in granulocyte apoptosis. ${ }^{12}$

The Jak enzymes act upstream of a family of eight transcription factors referred to as signal transducers and activators of transcription (STAT) proteins. ${ }^{14}$ Inactive STAT proteins are present in the cytoplasm. When stimulated, STAT proteins are first phosphorylated and then homodimerise or heterodimerise and translocate to the nucleus where they initiate transcription of STAT dependent genes. In granulocytes, specific STAT1, STAT3, and STAT5 activation proceeds from GM-CSF mediated Jak2 activation, suggesting that these members of the STAT family are implicated in the anti-apoptotic effects of GM-CSF. ${ }^{113} 15$ Recently, STAT5 has been found to be an 
essential factor in promoting GM-CSF dependent survival of differentiating myeloid progenitors. ${ }^{16}$ STAT5 favours the survival of these cells by inducing transcription of the $\mathrm{Bcl}-\mathrm{x}$ gene which encodes the anti-apoptotic Bcl-xL protein. ${ }^{16}$ STAT5 dependent induction of Bcl-xL has also been shown in red cell progenitors from STAT5 deficient mice ${ }^{17}$ and, furthermore, eosinophils treated with $\mathrm{Bcl}-\mathrm{xL}$ antisense oligodeoxynucleotides are less sensitive to the anti-apoptotic effects of GM-CSF than mock treated eosinophils. ${ }^{18}$ Taken together, these observations strongly suggest a role for STAT5 in delayed granulocyte apoptosis mediated by GM-CSF in vitro. However, the question of whether GM-CSF induced STAT5 activation is involved in delayed granulocyte apoptosis observed in inflammatory diseases, especially asthma, has never been addressed.

To solve this issue, it is necessary to use invasive procedures such as bronchoalveolar lavage (BAL) so the use of an asthma model rather than asthmatic subjects appears to be appropriate. Heaves is a common naturally occurring syndrome of horses which is characterised by episodes of acute airway obstruction (crises) followed by periods of disease remission. ${ }^{19} \mathrm{Cri}$ sis develops within several hours of exposing heaves susceptible horses to mouldy hay, indicating involvement of a hypersensitivity response to inhaled antigens that grow in damp hay. Antigens commonly implicated are borne by spores of Aspergillus fumigatus, Faenia rectivirgula, and Thermoactinomyces vulgaris. Clinical remission occurs after eviction of antigens when horses are pastured or stabled in a controlled environment. The principal lesion in heaves affected horses is bronchiolitis, while alveolitis is absent. Thus, heaves differs from human extrinsic allergic alveolitis. However, heaves shares certain characteristic features with asthma including recurrent airway obstruction, airway hyperresponsiveness, and chronic airway inflammation. Heaves is therefore considered to be the closest naturally occurring disease described in animals that parallels human asthma. ${ }^{20}$

In the present study we demonstrate enhanced ex vivo survival of lung granulocytes from heaves affected horses and provide evidence for involvement of the GM-CSF activated STAT5 signalling pathway in delaying apoptosis of lung granulocytes from this asthma model.

\section{Methods}

EXPERIMENTAL ANIMALS

Six horses of mean (SD) weight 501 (60) kg and 17.3 (2.4) years with a history and clinical signs of heaves were used in the study. These horses typically developed acute airway obstruction (crisis) when housed in a barn and fed mouldy hay, and entered clinical remission once pastured or stabled in a controlled environment. One month before the experiment they underwent a thorough clinical examination, including an electrocardiogram, arterial blood gas analysis, haematology, endoscopy of the airways, and tracheobronchial lavage. This confirmed that they suffered from heaves and were free from any other health problems. Six healthy horses (460 (36) kg; 7.3 (5.7) years) were used as controls. Experimental horses did not receive any medical treatment during the 4 weeks preceding and during the experiments. The protocol was approved by the ethics committee of the University of Liège.

Heaves affected horses were investigated during crisis. To obtain crisis the horses were stabled and subjected to a natural challenge with mouldy hay. The horses were considered to be in crisis when their breathing mechanical variables were within the following limits: maximal difference in pleural pressure $\geqslant 2.00 \mathrm{kPa}$, total pulmonary resistance $\geqslant 0.2 \mathrm{kPa} / 1 . \mathrm{s}$, and dynamic compliance $\leqslant 81 /$ $\mathrm{kPa}$. These respiratory mechanical variables were calculated from simultaneous measurements of oesophageal pressure and air flow. ${ }^{21}$

\section{PURIFICATION OF BLOOD AND LUNG}

\section{GRANULOCYTES}

Blood samples from healthy horses and heaves affected horses in crisis were withdrawn from the jugular vein and collected into $10 \mathrm{ml}$ heparinised tubes. Granulocytes were isolated from the anticoagulated blood by density centrifugation using the Histopaque gradient technique (Sigma Chemical Co, Bornem, Belgium). Purity, as determined by counting of cytospin preparations stained with DiffQuick (Dade Behring, Düdingen, Germany), was always $>95 \%$. Cell density was assessed by the use of a haemacytometer and cell viability, which was evaluated by trypan blue exclusion, was always $>90 \%$.

Lung granulocytes from healthy horses and heaves affected horses in crisis were obtained by BAL. Horses were premedicated intravenously with romifidine $0.01 \mathrm{mg} / \mathrm{kg}$ (Sedivet, Boehringer Ingelheim, Ingelheim, Germany). Bronchoalveolar lavage was performed using a $250 \mathrm{~cm} \times 9 \mathrm{~mm}$ fibreoptic endoscope wedged in the bronchi and by instilling in situ $200 \mathrm{ml}$ sterile saline at $37^{\circ} \mathrm{C}$. Recovery volume was always $>75 \%$. The granulocytes in the BAL fluid of heaves affected horses were not purified as they always contained $>90 \%$ granulocytes. Granulocytes from BAL fluid of healthy horses were purified by density centrifugation as described above. In this case, purity was always $>95 \%$. Cell density and viability were assessed as described above. Cell viability was always $>90 \%$. Because only $1.4(0.5) \%$ granulocytes were eosinophils, these cells were not separated from neutrophils.

\section{GRANULOCYTE CULTURE}

Blood and BAL fluid granulocytes were cultured at $2 \times 10^{6}$ per $\mathrm{ml}$ in RPMI 1640 medium (Life Technologies, Merelbeke, Belgium) supplemented with $1 \%$ glutamine, $10 \%$ fetal bovine serum, streptomycin $50 \mu \mathrm{g} / \mathrm{ml}$, penicillin $50 \mathrm{IU} / \mathrm{ml}$, gentamicin $50 \mu \mathrm{g} / \mathrm{ml}$, and amphotericin B $10 \mu \mathrm{g} / \mathrm{ml}$. Cells were cultured for 3, 24, or 48 hours before apoptosis determination or nuclear protein extraction. In neutralising experiments, granulocytes were cultured in the presence or absence of $5 \mu \mathrm{g} / \mathrm{ml}$ anti-GM-CSF receptor monoclonal antibodies 
(Sigma Chemical Co., Bornem, Belgium) or $5 \mu \mathrm{g} / \mathrm{ml}$ irrelevant mouse IgG as a control (sc 2025, Santa Cruz Biotechnology Inc, Santa Cruz, CA, USA) for 24 or 48 hours before analysis. In some experiments the granulocytes were also stimulated with $125 \mathrm{U} / \mathrm{ml}$ human recombinant GM-CSF for 24 or 48 hours before the apoptosis assay.

APOPTOSIS ASSAY

Cells were washed in phosphate buffered saline (PBS), resuspended in $100 \mu \mathrm{l}$ annexin-V binding buffer containing annexin-V-fluorescein and propidium iodide (Roche Diagnostics, Brussels, Belgium), incubated for 15 minutes at room temperature in the dark, and analysed using epifluorescence microscopy. Apoptotic cells were counted by two investigators.

NUCLEAR PROTEIN EXTRACTION

Nuclear proteins were extracted as previously defined $^{22}$ with slight modifications. Cytoplasmic buffer incorporated $10 \mathrm{mM}$ Hepes, $\mathrm{pH}$ 7.9, $10 \mathrm{mM} \mathrm{KCl}, 2 \mathrm{mM} \mathrm{MgCl}_{2}, 0.1 \mathrm{mM}$ ethylenediaminetetraacetic acid (EDTA), $0.2 \%$ (vol $/ \mathrm{vol}$ ) Nonidet P-40, $1.6 \mathrm{mg} / \mathrm{ml}$ protease inhibitors (Complete; Boehringer Mannheim, Mannheim, Germany), $3 \mathrm{mM}$ of the protease inhibitor diisopropyl fluorophosphate (DFP, Sigma Chemical Co, Bornem, Belgium), $1 \mathrm{M} \mathrm{NaF}$, and $0.5 \mathrm{M} \mathrm{Na}_{3} \mathrm{VO}_{4}$. The pelleted nuclei were resuspended in $20 \mathrm{mM}$ Hepes, pH 7.9, $1.5 \mathrm{mM} \mathrm{MgCl}_{2}, 0.2 \mathrm{mM}$ EDTA, $0.63 \mathrm{M} \mathrm{NaCl}, 25 \%$ (vol/vol) glycerol, $1.6 \mathrm{mg} / \mathrm{ml}$ protease inhibitors, $3 \mathrm{mM} \mathrm{DFP}$, $1 \mathrm{M} \mathrm{NaF}$, and $0.5 \mathrm{M} \mathrm{Na}_{3} \mathrm{VO}_{4}$ (nuclear buffer), incubated for 20 minutes at $4^{\circ} \mathrm{C}$, and centrifuged for 30 minutes at $14000 \mathrm{rpm}$ (Centrifuge 5415C, Eppendorf, Hamburg, Germany). Protein concentrations were measured with the Micro BCA protein assay reagent kit (Pierce, Rockford, IL, USA).

STAT5 ELECTROPHORETIC MOBILITY SHIFT ASSAYS (EMSAS)

Binding reactions were performed for $30 \mathrm{~min}$ utes at room temperature with $5 \mu \mathrm{g}$ nuclear proteins in $20 \mathrm{mM}$ Hepes, $\mathrm{pH} 7.9,10 \mathrm{mM}$ $\mathrm{KCl}, 0.2 \mathrm{mM}$ EDTA, $20 \%$ (vol/vol) glycerol, $1 \%(\mathrm{wt} / \mathrm{vol}$ ) acetylated bovine serum albumin, $3 \mu \mathrm{g}$ poly $(\mathrm{dI}-\mathrm{dC})$ (Amersham Pharmacia Biotech, Little Chalfont, UK), $1 \mathrm{mM}$ dithiothreitol, $1 \mathrm{mM}$ phenylmethylsulfonyl fluoride, and $100000 \mathrm{cpm}{ }^{32}$ P-labelled double stranded oligonucleotide probes. Probes were prepared by annealing the appropriate single stranded oligonucleotides (Eurogentech, Liège, Belgium) at $65^{\circ} \mathrm{C}$ for 10 minutes in $10 \mathrm{mM}$ Tris, $1 \mathrm{mM}$ EDTA, $10 \mathrm{mM} \mathrm{NaCl}$, followed by slow cooling to room temperature. The probe used in this study was the $21 \mathrm{bp}$ GAS-like element from the promoter of the bovine $\beta$-casein ${ }^{23}$ 5'-AGATTTCTAGGAATTCAAATC-3'. The mutated probe was 5'-AGATTTCTAATC GTTCAAATC-3'. The probes were then labelled by end filling with the Klenow fragment of Escherichia coli DNA polymerase I (Boehringer Mannheim, Mannheim, Germany), with phosphorus-32-deoxyadenosine triphosphate ( ${ }^{32} \mathrm{P}$-dATP) and phosphorus-32deoxycytidine triphosphate ( $\left.{ }^{32} \mathrm{P}-\mathrm{dCTP}\right)$ (Dupont-New England Nuclear (NEN) Life Science Products, Les Ulis, France). Labelled probes were purified by spin chromatography on Sephadex G-25 columns. DNA-protein complexes were separated from unbound probe on $4 \%$ native polyacrylamide gels at $150 \mathrm{~V}$ in $0.25 \mathrm{M}$ Tris, $0.25 \mathrm{M}$ sodium borate, and $0.5 \mathrm{mM}$ EDTA, $\mathrm{pH}$ 8.0. Gels were vacuum dried and exposed to Fuji $x$ ray film at $-80^{\circ} \mathrm{C}$ for $12-48$ hours. To confirm specificity, competition assays were performed with a 50-fold excess of unlabelled wild type and mutated probes. Moreover, binding of the non inducible transcription factor OCT-1 was used as an internal standard. The OCT- 1 probe was as follows: 5' TGTCGAATGCAAATCACTAGAA 3'. For supershifting experiments, $1.5 \mu \mathrm{l}$ of each antibody was incubated with the extracts for 30 minutes before the addition of the radiolabelled probe. The antibodies used in these experiments were the following: (a) a rabbit antibody recognising the carboxy terminus of STAT5a (sc 1081, Santa Cruz Biotechnology Inc); (b) a rabbit antibody directed to the carboxy terminus of STAT5b (sc 835, Santa Cruz Biotechnology Inc).

STATISTICAL ANALYSIS

Data are presented as mean (SE). The differences between mean values were estimated by use of Student's $t$ tests for unpaired data. A $p$ value of $<0.05$ was considered as significant.

\section{Results}

LUNG GRANULOCYTES FROM HEAVES AFFECTED HORSES HAVE A SIGNIFICANT DELAY IN APOPTOSIS Exposure of heaves affected horses to antigens found in mouldy hay induced the rapid mobilisation of granulocytes into the airway lumen. To determine the existence of a delay in apoptosis in BAL fluid granulocytes, potentially contributing to the characteristic persistence of inflammation in heaves, BAL fluid and blood granulocytes obtained from healthy and heaves affected horses were cultured ex vivo for 3, 24, or 48 hours and analysed for signs of apoptosis using the Annexin-V/propidium iodide detection method. At 3 hours, BAL fluid granulocytes from heaves affected horses and blood granulocytes from healthy and diseased horses had low and similar levels of apoptosis (fig 1). Conversely, at this time the rate of apoptosis was 38 (5) $\%$ in BAL fluid granulocytes from healthy horses (fig 1). At 24 and 48 hours, BAL fluid granulocytes from heaves affected horses showed a significant delay in apoptosis compared with blood granulocytes from healthy and diseased horses and BAL fluid granulocytes from healthy horses (fig 1). The rate of apoptosis in blood granulocytes recovered from healthy and heaves affected horses was comparable, whereas the rate of apoptosis was significantly higher in BAL fluid granulocytes from healthy horses (fig 1). These results indicate that anti-apoptotic mechanisms enhance the survival of granulocytes that have migrated from the blood to the lung in heaves affected horses. 


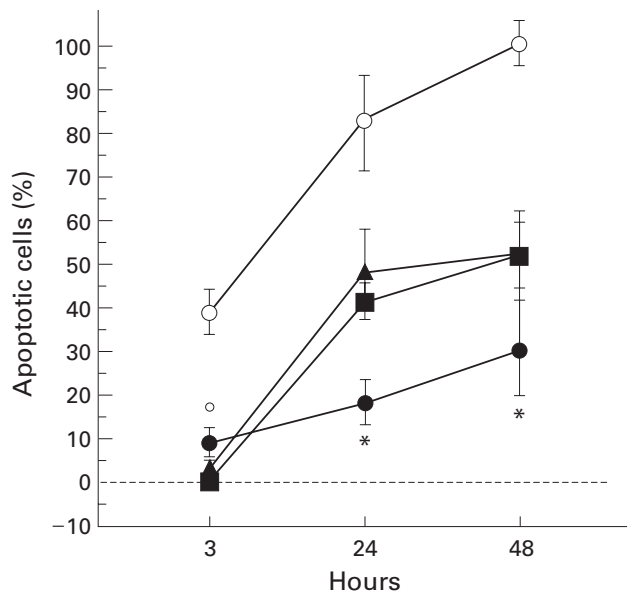

Figure 1 Ex vivo kinetics of apoptosis of blood and BAL fluid granulocytes from healthy horses $(\mathbf{\square}=$ blood; $\bigcirc=$ $B A L$ fluid) and heaves affected horses in crisis ( $\mathbf{\Lambda}=$ blood; - = BAL fluid). *Significantly different from values obtained with blood granulocytes from healthy and diseased horses and BAL fluid granulocytes from healthy horses; significantly different from values obtained with $B A L$ fluid granulocytes from healthy horses.

AUTOCRINE GM-CSF CONTRIBUTES TO THE ENHANCED SURVIVAL OF BAL FLUID GRANULOCYTES FROM HEAVES AFFECTED HORSES GM-CSF, which is produced by numerous activated cells including granulocytes themselves, ${ }^{2}$ is a potent inhibitor of spontaneous granulocytic apoptosis. ${ }^{7}$ To establish the involvement of GM-CSF, especially autocrine GM-CSF, in enhanced survival of BAL fluid granulocytes from heaves affected horses, samples of BAL fluid from diseased horses in crisis were cultured in the presence or absence of $5 \mu \mathrm{g} / \mathrm{ml}$ anti-GM-CSF receptor antibodies or $5 \mu \mathrm{g} / \mathrm{ml}$ control antibodies for 24 and 48 hours before apoptosis assessment. As shown in fig 2, there was no evidence for apoptosis in cells that had been in culture for 3 hours. At 24 hours the percentages of treated and untreated apoptotic granulocytes were similar (fig 2). In contrast, at 48 hours the rate of apoptosis rose significantly in granulocytes treated with anti-GM-CSF receptor antibodies compared with untreated cells and cells treated with control antibodies (fig 2). Anti-GM-CSF receptor antibodies had no effect on the rate of apoptosis in blood granulocytes from healthy and heaves affected horses (data not shown). These results suggest that granulocytes that have migrated from blood to inflamed lung secrete GM-CSF and demonstrate that autocrine GM-CSF is involved in the delayed apoptosis of BAL fluid granulocytes from heaves affected horses.

AUTOCRINE GM-CSF MAXIMALLY INDUCES APOPTOSIS DELAY IN LUNG GRANULOCYTES FROM HEAVES AFFECTED HORSES

To determine whether exogenous GM-CSF inhibits spontaneous apoptosis in blood granulocytes from healthy and heaves affected horses and increases the delay in apoptosis in BAL fluid granulocytes from diseased horses, these cells were cultured in the presence or absence of an optimal dose of GM-CSF (125 U/ml) for 3,24 , and 48 hours before apoptosis detection. At 3 hours apoptosis was nearly undetectable

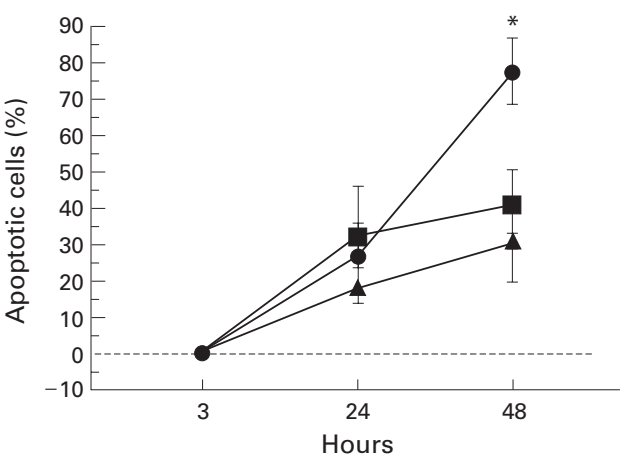

Figure 2 Effects of anti-GM-CSF receptor antibodies on ex vivo kinetics of apoptosis of BAL fluid granulocytes from heaves affected horses in crisis. Cells were cultured in the presence or absence $(\boldsymbol{\Delta})$ of $5 \mu \mathrm{g} / \mathrm{ml}$ anti-GM-CSF receptor antibodies (•) or $5 \mu \mathrm{g} / \mathrm{ml}$ irrelevant mouse IgG as a control (घ). *Significantly different from values obtained with untreated granulocytes and granulocytes treated with control antibodies.

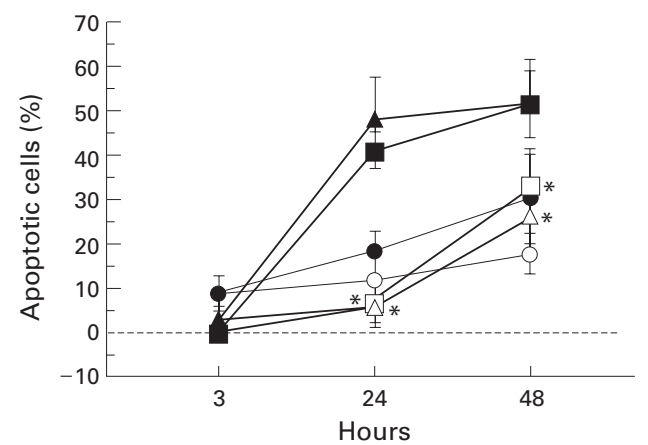

Figure 3 Effects of GM-CSF on ex vivo kinetics of apoptosis of blood granulocytes from healthy $(\square$, treated; $\mathbf{\square}$ untreated) and heaves affected horses $(\triangle$, treated; $\boldsymbol{\Delta}$, untreated) and BAL fluid granulocytes from heaves affected horses ( $\mathrm{O}$ treated; $\bullet$, untreated). Cells were cultured in the presence or absence of $125 \mathrm{U} / \mathrm{ml}$ human recombinant GM-CSF ${ }^{\star}$ Significantly different from values obtained with untreated cells.

in both stimulated and non-stimulated cells (fig 3). At 24 and 48 hours stimulated blood granulocytes from healthy and heaves affected horses showed a significant increase in survival compared with non-stimulated cells (fig 3). Conversely, the rate of apoptosis in untreated and treated BAL fluid granulocytes from diseased horses was comparable (fig 3). Differences between the rate of apoptosis in treated blood granulocytes from healthy and heaves affected horses and treated and untreated BAL fluid granulocytes from diseased horses were not statistically significant (fig 3). These data indicate that BAL fluid granulocytes from heaves affected horses are no more sensitive to GM-CSF than blood granulocytes from healthy and diseased horses and show that BAL fluid granulocytes from heaves affected horses are maximally stimulated by GM-CSF at the site of inflammation.

ROLE OF STAT5 IN GM-CSF DEPENDENT INCREASED SURVIVAL OF BAL FLUID GRANULOCYTES FROM HEAVES AFFECTED HORSES GM-CSF induces the activation of STAT5 in human granulocytes through which gene transcription is regulated. ${ }^{13}$ To investigate the 
A
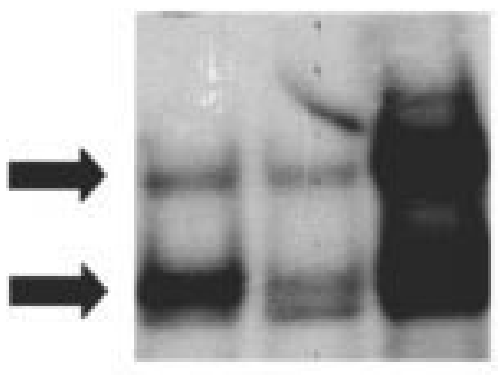

1

2

3

B

OCT-1
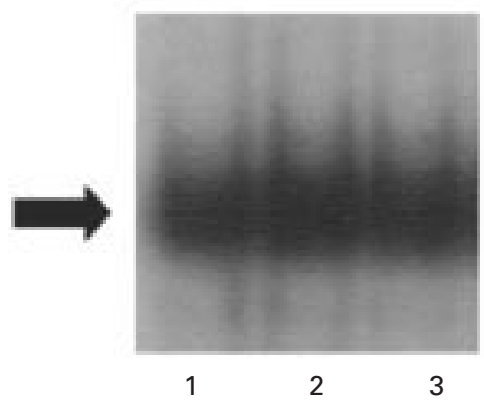

C

STAT5
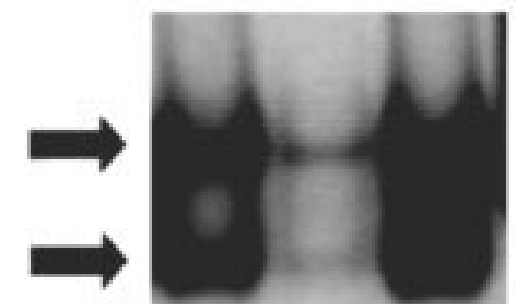

$\longrightarrow$

D

STAT 5

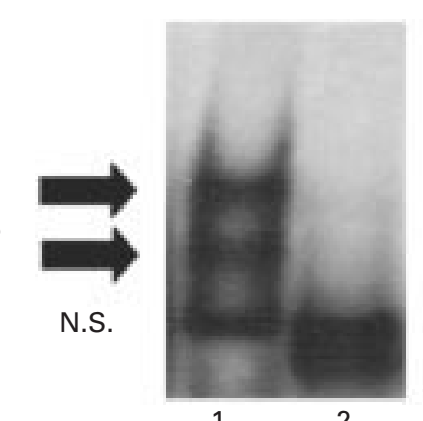

1

2
A

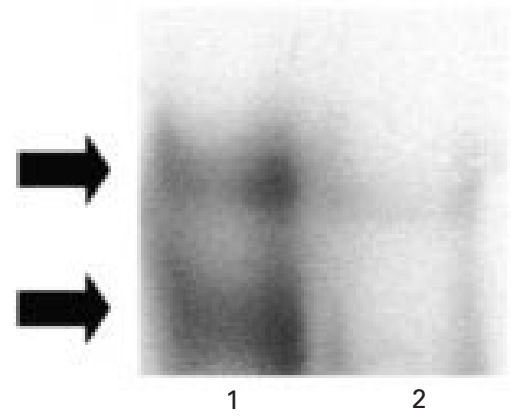

B

OCT-1

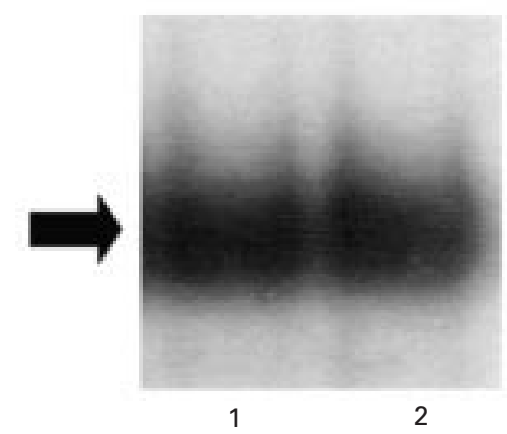

Figure 5 Effects of anti-GM-CSF receptor antibodies on STAT5 activity in ex vivo cultured BAL fluid granulocytes from heaves affected horses in crisis. (A) Ex vivo cultured granulocytes obtained from heaves affected horses in crisis were incubated for 24 hours with $5 \mu \mathrm{g} / \mathrm{ml}$ anti-GM-CSF receptor antibodies. Nuclear extracts were prepared from untreated (lane 1) and treated (lane 2) granulocytes and were subsequently analysed for STAT5 binding activity by electrophoretic mobility shift assay (EMSA). (B) As an internal control, OCT-1 binding activity was assessed in the same extracts. All the experiments shown in this figure are representative of six similar experiments. Solid arrows indicate specific complexes.

horses were analysed for STAT5 binding activity by EMSA (fig 4). STAT5 complexes were made of two bands (fig 4A). Considerable amounts of activated STAT5 were detected in BAL fluid granulocytes from heaves affected horses (fig 4A, lane 3). Conversely, lower quantities of activated STAT5 were observed in nuclear extracts from blood granulocytes of healthy and heaves affected horses (fig 4A, lanes 1 and 2, respectively).

Equal loading of the gels was confirmed by assessment of the binding of the non-inducible transcription factor OCT-1. OCT-1 binding activity was no different in blood granulocytes from healthy and heaves affected horses and in BAL fluid granulocytes from heaves affected horses (fig 4B). To confirm specificity of STAT5 complexes, competition experiments were performed using an excess of unlabelled and mutated $\beta$-casein probes (fig $4 \mathrm{C}$ ). Supershift experiments were performed to confirm that STAT5 proteins were present in the shifted complexes. Both specific bands were completely lost after incubation with both antiSTAT5a and anti-STAT5b antibodies (fig 4D), confirming that the shifted bands are made of STAT5 proteins.

To determine whether increased STAT5 activity in BAL fluid granulocytes from diseased horses was dependent on GM-CSF receptor activation, $5 \mu \mathrm{g} / \mathrm{ml}$ anti-GM-CSF receptor antibodies were added to BAL fluid granulocytes from heaves affected horses in 
crisis cultured for 3 hours. Nuclear extracts were prepared 24 hours after antibody addition and were subsequently analysed for STAT5 and OCT-1 binding activity by EMSA (fig 5). OCT-1 binding activity was similar in treated and untreated cells (fig 5B), whereas anti-GMCSF receptor antibodies markedly reduced STAT5 activity in BAL fluid granulocytes from affected horses (fig 5A, lane 2), suggesting that STAT5 activation may be implicated in the anti-apoptotic effect of GM-CSF on lung granulocytes from heaves affected horses.

\section{Discussion}

A reduction in inflammatory cell apoptosis is a central concept in the maintenance of inflammation and a potential target in the resolution of inflammation in many inflammatory diseases. ${ }^{24}$ It has previously been shown that neutrophil apoptosis in BAL fluid and blood is delayed in several inflammatory diseases including cystic fibrosis, idiopathic fibrosis, pneumonia, and cancer associated with neutrophilia. ${ }^{2}$ Moreover, blood eosinophil apoptosis is delayed in asthma ${ }^{4}$ and fewer apoptotic eosinophils are found in bronchial mucosal biopsy specimens from asthmatic patients than in patients with chronic bronchitis, ${ }^{5}$ suggesting that an enhanced survival of eosinophils could contribute to the persistence of inflammation in asthma. In the present study we have investigated for the first time the ex vivo kinetics of apoptosis in BAL fluid granulocytes obtained from an animal model of asthma. An apoptotic delay was observed in these cells over a period of 48 hours, confirming the likely contribution of survival factors to the persistent inflammation associated with the disease. Interestingly, in our study the apoptotic rates of blood granulocytes from diseased and healthy horses were similar, suggesting that the survival factors involved in delayed granulocyte apoptosis mainly accumulate at the site of inflammation and only affect granulocytes that have extravasated into the inflamed lung.

It has been established that GM-CSF is a key contributory factor in a number of inflammatory diseases and has been shown to function in vitro and in vivo as a potent inhibitor of neutrophil and eosinophil apoptosis. ${ }^{25}{ }^{26}$ Significant increases in GM-CSF have been reported in BAL fluid and biopsy tissue from asthmatic subjects, and significant positive correlations exist between GM-CSF in biopsy tissue and BAL fluid and biopsy eosinophils. ${ }^{27}$ Numerous cell types are able to produce GM-CSF, thereby exerting an effect on recruited granulocytes. For instance, in patients with bronchial asthma activated $\mathrm{T}$ cells producing GM-CSF have been located at the site of allergic inflammation associated with eosinophilia. ${ }^{28}$ Additionally, endothelial cells, epithelial cells, and macrophages have also been found to produce GM-CSF in vivo. ${ }^{25}$ Nevertheless, it has been shown that GM-CSF is produced by pulmonary granulocytes from patients with inflammatory diseases of the lung, ${ }^{2}$ especially by airway eosinophils in asthma, ${ }^{29}$ suggesting that autocrine GM-CSF also participates in delayed granulocyte apoptosis. This assumption is reinforced by the fact that neutralisation of GM-CSF increases the rate of apoptosis in ex vivo cultured blood eosinophils from asthmatic patients. ${ }^{4}$ In the present study the addition of anti-GM-CSF receptor antibodies to ex vivo cultured BAL fluid granulocytes obtained from heaves affected horses in crisis induced an increased rate of apoptosis in contrast to the heightened survival of untreated cells, unambiguously demonstrating the involvement of autocrine GM-CSF in enhanced lung granulocyte survival associated with the asthma-like condition.

Recent research has shown that the STAT5 signalling pathway is an important mediator of GM-CSF induced biological responses, especially enhancement of cell survival. ${ }^{16}$ Indeed, bone marrow cells from STAT5 deficient mice display a significant increase in apoptotic cell death during functional maturation, despite the presence of GM-CSF which usually confers resistance to apoptosis. In conjunction with the implication of the STAT5 signalling pathway in effecting actions induced by GM-CSF, the anti-apoptotic effect of GMCSF on inflammatory cells from heaves affected horses potentially engaged STAT5 to participate in the mechanisms leading to the persistence of inflammation in asthmatic airways. Accordingly, we investigated STAT5 activity in inflammatory cells from heaves affected horses and demonstrated for the first time the presence of increased levels of activated STAT5 in lung granulocytes from animals suffering from an asthma-like condition. Moreover, anti-GM-CSF receptor antibodies markedly reduced STAT5 activity in ex vivo cultured BAL fluid granulocytes from diseased horses, indicating that STAT5 activation in these cells depends on the presence of GM-CSF, and that STAT5 is probably involved in GM-CSF induced resistance to apoptosis in asthmatic airway granulocytes. Importantly, the induction of the STAT5 activation pathway in recruited inflammatory cells questions the potential STAT5 induced transcription of the anti-apoptotic protein Bcl-xl, based on current research indicating the anti-apoptotic activities of STAT5 in myeloid progenitor cells through its ability to induce transcription of the $b c l-x$ gene. ${ }^{16}$ Finally, the likely involvement of the STAT5 signalling pathway in granulocyte survival provides a new perspective for the treatment of chronic inflammatory diseases such as asthma.

Renata Turlej and Laurence Fiévez contributed equally to this work. The authors thank Drs Vincent Bours, Marie-Paule Merville, Renaud Louis, and Alain Vanderplasschen for advice, and Carine Gresse, Martine Leblond, Michel Motkin, Jean-François Rouelle, and Ihlam Sbaï for excellent technical and secretarial assistance.

Funding: This study was supported by grants from UCB Pharma (Belgium), and the Ministère de la Région Wallonne (Belgium). FB is Research Assistant at the National Fund for Scientific Research (Belgium). LF and NK are supported by FRIA fellowships (Belgium).

1 Barnes PJ. Pathophysiology of asthma. Br f Clin Pharmacol 1996;42:3-10. 
2 Dibbert B, Weber M, Nikolaizik WH, et al. Cytokinemediated Bax deficiency and consequent delayed neutrophil apoptosis: a general mechanism to accumulate effector cells in inf

3 Wedi B, Raap U, Lewrick H, et al. Delayed eosinophil programmed cell death in vitro: a common feature in inhalan allergy and extrinsic and intrinsic atopic dermatitis. $f$ Allergy Clin Immunol 1997;100:536-43.

4 Kankaanranta H, Lindsay MA, Giembycz MA, et al. Delayed eosinophil apoptosis in asthma. F Allergy Clin Immunol 2000;106:77-83.

5 Vignola AM, Chanez P, Chiappara G, et al. Evaluation of apoptosis of eosinophils, macrophages, and $\mathrm{T}$ lymphocytes in mucosal specimens of patients with asthma and chronic bronchitis. F Allergy Clin Immunol 1999;103:563-73.

6 Sousa AR, Poston RN, Lane SJ, et al. Detection of GM-CSF in asthmatic bronchial epithelium and decrease by inhaled corticosteroids. Am Rev Respir Dis 1993;147:1557-61.

7 Colotta F, Polentarutti FRN, Sozzani S, et al. Modulation of granulocyte survival and programmed cell death by granulocyte survival and programmed cell death by

8 Gearing DP, King JA, Gough NM, et al. Expression cloning of a receptor for human granulocyte-macrophage colonyof a receptor for human granulocyte-macrop
stimulating factor. $E M B O \mathcal{F} 1989 ; 8: 3667-76$.

9 Hayashida K, Kitamura T, Gorman DM, et al. Molecular cloning of a second subunit of the receptor for human granulocyte-macrophage colony-stimulating factor (GM$\mathrm{CSF})$ : reconstitution of a high-affinity GM-CSF receptor Proc Natl Acad Sci USA 1990;87:9655-9.

10 Thompson NT, Randall RW, Garland LG. Role of c-lyn in the functional effects of GM-CSF on human neutrophils. Biochem Soc Trans 1995;23:196S.

11 Brizzi MF, Aronica MG, Rosso A, et al. Granulocytemacrophage colony-stimulating factor stimulates JAK2 signaling pathway and rapidly activates p93fes, STAT1 p91, and STAT3 p92 in polymorphonuclear leukocytes. $\mathcal{F}$ Biol Chem 1996;271:3562-7.

12 Simon HU, Yousefi S, Dibbert B, et al. Anti-apoptotic signals of granulocyte-macrophage colony-stimulating fac-
tor are transduced via Jak2 tyrosine kinase in eosinophils. tor are transduced via Jak2 tyrosing
Eur f Immunol 1997;27:3536-9.

13 Al-Shami A, Naccache PH. Granulocyte-macrophage colony-stimulating factor-activated signaling pathways in human neutrophils. Selective activation of Jak2, Stat3, and Stat5B. F Biol Chem 1999;274:5333-8.

14 Hoey T, Grusby MJ. STATs as mediators of cytokineinduced responses. Adv Immun 1999;71:145-62.

$15 \mathrm{M}^{\mathrm{c}}$ Donald PP, Bovolenta C, Cassatela MA. Activation of distinct transcription factors in neutrophils by bacterial LPS, interferon- $\gamma$ and GM-CSF and the necessity to overcome the action of endogenous proteases. Biochemistry 1998;37:13165-73.
16 Kieslinger M, Woldman I, Moriggl R, et al. Antiapoptotic activity of STAT5 required during terminal stages of
myeloid differentiation. Gen Dev 1999;14:232-44.

17 Socolovski M, Fallon AE, Fallon J, et al. Fetal anemia and apoptosis of red cell progenitors in Stat 5 in Bcl-XL induction. Cell 1999;98:181-91.

18 Dibbert B, Daigle I, Schranz C, et al. Role for Bcl-xL in delayed eosinophil apoptosis mediated by granulocytemacrophage colony-stimulating factor and interleukin-5. Blood 1998;92:778-83.

19 Robinson NE, Derksen FJ, Olszewski MA, et al. The pathogenesis of chronic obstructive pulmonary disease of horses. Br Vet f 1996;152:283-306.

20 Snapper JR. Large animal models in asthma. Am Rev Respir Dis 1986;133:351-2.

21 Art T, Duvivier DH, Votion D, et al. Does an acute COPD crisis modify the cardiorepiratory and ventilatory adjustments to excercise in horses? f Appl Physiol 1998,84:84552

22 Bureau F, Bonizzi G, Kirschvink N, et al. Correlation between nuclear factor-kappaB activity in bronchial brushing samples and lung dysfunction in an animal model of asthma. Am f Respir Crit Care Med 2000;161:1314-21.

23 Gouilleux F, Pallard C, Dunanster-Fourt I, et al. Prolactin, growth hormone, erythropoietin and granulocytemacrophage colony stimulating induce MGF-Stat 5 DNA binding activity. $E M B O 71995 ; 14: 2005-13$.

24 Haslett C. Granulocyte apoptosis and its role in the resolution and control of lung inflammation. Am 7 Respir Crit Care Med 1999;160:S5-11.

25 Coxon A, Tang T, Mayadas TN. Cytokine-activated endothelial cells delay neutrophil apoptosis in vitro: a role for granulocyte/macrophage colony-stimulating factor. $\mathcal{F}$ Exp Med 1999;190:923-33.

26 Tai PC, Sun L, Spry CJ. Effects of IL-5, granulocyte/ macrophage colony-stimulating factor (GM-CSF) and IL-3 on the survival of human blood eosinophils in vitro. Clin Exp Immunol 1991;85:312-16.

27 Woolley KL, Adelroth E, Wooley MJ, et al. Granulocytemacrophage colony-stimulating factor, eosinophils and macrophage colony-stimulating factor, eosinophils and mild, stable, atopic asthma. Eur Respir f 1994;7:1576-84.

28 Till S, Li B, Durham S, et al. Secretion of the eosinophil-active cytokines interleukin-5, granulocyte/ macrophage colony-stimulating factor and interleukin- 3 by bronchoalveolar lavage CD4+ and CD8+ T cell lines in atopic asthmatics, and atopic and non-atopic controls. Eur f Immunol 1995;25:2727-31.

29 Broide DH, Paine MM, Firestein GS. Eosinophils express interleukin 5 and granulocyte macrophage-colonystimulating factor mRNA at sites of allergic inflammation in asthmatics. F Clin Invest 1992;90:1414-24. 